\title{
Loop Electrosurgical Excision
}

National Cancer Institute

\section{Source}

National Cancer Institute. Loop Electrosurgical Excision. NCI Thesaurus. Code C51760.

Uses a thin, low-voltage electrified wire loop to cut out a thin layer of abnormal tissue; generally used to remove abnormal cells on the surface of the cervix. 